\title{
EL CAMPO DE LA JUSTICIA TRANSICIONAL
}

\author{
The field of transitional justice
}

\author{
Carlos Felipe Rúa Delgado*
}

"Cubre con planchas de oro el crimen, y la terrible lanza de la justicia se romperá, impotente, ante él”. William Shakespeare - "El Rey Lear".

\section{RESUMEN}

La justicia transicional corresponde a un paradigma jurídico que permite la transición de un estado de conflicto a uno de cesación del conflicto. Este paradigma puede analizarse como un campo, siguiendo la teoría de Pierre Bourdieu, lo cual facilita la tarea de interpretación de las tensiones que subyacen entre diferentes actores e intereses que entran en el juego. En este texto se realiza una aproximación a la configuración del campo de la justicia transicional, tomando como referencia el caso colombiano.

Palabras clave: Campo, justicia transicional, conflicto, estándares, Bourdieu.

\footnotetext{
* Facultad de Derecho y Ciencias Políticas de la Universidad de San Buenaventura Cali. Cali, Colombia. Docente investigador reconocido por Colciencias en la categoría de Investigador Asociado, adscrito al Grupo de Investigación Problemas Contemporáneos del Derecho y la Política (GIPCODEP), reconocido en categoría A por Colciencias. Correo electrónico: cfrua@usbcali.edu.co
}

Artículo recibido el 26 de agosto de 2015. Aceptado el 19 de mayo de 2017. 


\begin{abstract}
Transitional justice corresponds to a legal paradigm that lets the transition between a situation of conflict to a cessation of conflict. This paradigm may be analyzed like a field, following the Pierre Bourdieu's theory, if make easy the work of interpretation about the tensions that underlying between actors and interests that play. In this text makes an approach to configuration of transitional justice field, taking like reference the Colombian case.
\end{abstract}

Keywords: Field, transitional justice, conflict, standards, Bourdieu.

\title{
Introducción
}

La lucha contra la impunidad se constituye en la razón ética que posibilitó la aparición de la justicia transicional. Si bien la pregunta por la justicia cobró auge en el siglo XX a partir del trabajo de pensadores como Kelsen, Rawls, Bobbio, Dworkin, Sen, Nussbaum, MacIntyre o Sandel, por citar a algunos de los más conocidos, es a partir de la situación presentada en los juicios de Núremberg en donde autores como Teitel (2009) cifran el principio de la justicia transicional. Vale decir que en estos juicios se hizo plausible el problema que representaba la sanción a los jerarcas del Tercer Reich por haber dado cumplimiento a las leyes positivas emitidas por el Estado, lo que a la postre determinó una ruptura con el positivismo a partir de la aplicación de la fórmula de Radbruch (2009: 34), según la cual "el conflicto entre la justicia y la seguridad jurídica debió resolverse con la primacía del derecho positivo sancionado por el poder, aun cuando por su contenido sea injusto e inconveniente, a no ser que la contradicción de la ley positiva con la justicia alcance una medida tan insoportable, que deba considerarse "como falso derecho" y ceder el paso a la justicia". En defensa de dicha fórmula y reiterando la ruptura positivista, Alexy (2001: 77), señaló que “quien sustente esta tesis ha dejado de ser iuspositivista. Si un positivista quiere establecer qué 
es el Derecho, sólo pregunta por la legalidad conforme al ordenamiento y la eficacia social, siendo estos dos elementos del concepto positivista de Derecho, como muestran las numerosas variedades del positivismo jurídico, susceptibles de muy distintas interpretaciones y valoraciones".

La importancia de la aplicación de la fórmula de Radbruch deviene del hecho de haber constituido un elemento esencial de fundamentación del discurso de los derechos humanos, además de criterio orientador que permite la búsqueda de nuevas formas de justicia, aun cuando subsistan normas legales que terminen convirtiéndose en obstáculo. Por ello Vassalli (2014: 266), refiriéndose a la trascendencia de la fórmula de Radbruch en un medio jurídico como el alemán, expone que:

más que una fórmula, la del derecho intolerablemente injusto devino un dogma, según alguien, toda una filosofía. En todo caso, ha sido la tabla de salvación, el criterio esencial que ha orientado a la jurisprudencia alemana por decenios y decenios y que todavía subsiste. Un esquema dentro del cual encerrar o del cual excluir determinados supuestos respecto de los que el juez debe decidir.

La fórmula de Radbruch sirvió como razón justificatoria, no solo para la ruptura con el positivismo jurídico estricto, sino también para la resignificación de lajusticia a partir de un contexto de respeto por los derechos humanos, en donde estos empiezan a gozar de reconocimiento expreso en diversos instrumentos internacionales con plena fuerza vinculante. Papacchini (2003: 51) encuentra un poder moral para el reconocimiento de los derechos humanos, dado que, “después de la segunda guerra mundial, este poder moral queda vigorizado además por el reconocimiento por parte de la comunidad internacional, lo que permite a individuos, grupos o minorías reclamar la protección y el amparo de instituciones creadas por el poder de la humanidad civilizada". Ese poder moral al que se refiere el autor, no es cosa diferente al reconocimiento del carácter moral que subyace a los derechos humanos como rezago -o reivindicacióndel iusnaturalismo, por ello puede señalarse que "los derechos humanos surgen 
como aspiraciones morales que necesitan cierto grado de formulación jurídica. Esto ha llevado a algunos teóricos a decir que los derechos se ubican en la encrucijada de lo moral y de lo jurídico" (Papacchini, 2003: 50).

Uno de los frutos del reconocimiento de los derechos humanos radica en la conversión de los mismos en el cinturón de los estados en la lucha contra la impunidad, a través del establecimiento de estándares internacionales, los cuales son definidos por Quinche (2009: 27) como:

los parámetros básicos exigibles desde el derecho internacional de los derechos humanos, el derecho internacional humanitario (DIH), y el derecho penal internacional, al interior de un proceso de transición en cualquier Estado o sociedad, en la medida en que son la forma material de distintos consensos de la comunidad internacional, alrededor del interés común de la lucha contra la atrocidad y la impunidad.

La justicia transicional implica entonces la incorporación de los derechos humanos, a modo de estándares, en un modelo de justicia aplicable a escenarios en donde es necesaria una transición, lo que implica que las normas de justicia transicional se estructuran sobre dos referentes a saber: uno jurídico, que se refiere a la incorporación de los estándares en derechos humanos y uno político que se refiere a la transición en sí (Rúa Delgado, 2015: 78-79).

Por representar una lucha contra la impunidad aceptada por los Estados, hoy en día resulta impensable abordar un proceso de negociación política con miras a la superación de un conflicto interno sin que se aborde la adaptación del modelo de justicia transicional al contexto determinado. Aun así, existen patrones generales de identificación que entran en tensión a partir de actores e intereses que permiten la caracterización de la justicia transicional como un campo, a la luz de la teoría de Bourdieu. 


\section{El concepto de campo según Bourdieu}

El campo es un concepto relacional que, para su comprensión, requiere de la identificación de los actores que entran en juego. Dicho concepto se refiere a las relaciones entre actores e intereses y las tensiones que se generan a partir de estas relaciones. En la sociología contemporánea, el campo es definido por Bourdieu y Wacquant (2005: 150):

como una red o una configuración de relaciones objetivas entre posiciones. Estas posiciones están se objetivamente definidas, en su existencia y en las determinaciones que imponen sobre sus ocupantes, agentes o instituciones, por su situación presente y potencial (situs) en la estructura de la distribución de las especies del poder (o capital) cuya posesión ordena el acceso a ventajas específicas que están en juego en el campo, así como por su relación objetiva con otras posiciones (dominación, subordinación, homología, etc.).

El campo es fundamental para la comprensión de las reglas que rigen las estructuras sociales (Leyton, 2014: 170-171), dado que el mundo social, según Bourdieu (2000: 127) se rige por “estructuras objetivas, independientes de la conciencia y de la voluntad de los agentes, que son capaces de orientar y de coaccionar sus prácticas y sus representaciones". En tal sentido, el concepto de campo permite la comprensión de los procesos socioculturales al establecer los puentes metodológicos - como el campo- que permitan articular los niveles estructurales de la sociedad con las prácticas de los actores intervinientes (Vizcarra, 2002: 56).

Cada campo goza de unas propiedades específicas, aun cuando gozan de unos elementos generales que permiten su configuración, lo que no resta su especificidad, debido a que las tensiones que subyacen en su interior son muy propias, tal y como explica Bourdieu (2002: 119-120):

Los campos se presentan para la aprehensión sincrónica como espacios estructurados de posiciones (o de puestos) cuyas propiedades dependen de su posición en dichos espacios y pueden analizarse en 
forma independiente de las características de sus ocupantes (en parte determinados por ellas). Existen leyes generales de los campos: campos tan diferentes como el de la política, el de la filosofía o el de la religión tienen leyes de funcionamiento invariantes (gracias a esto el proyecto de una teoría general no resulta absurdo y ya desde ahora es posible utilizar lo que se aprende sobre el funcionamiento de cada campo en particular para interrogar e interpretar a otros campos, con lo cual se logra superar la antinomia mortal de la monografía ideográfica y de la teoría formal y vacía). Cada vez que se estudia un nuevo campo, ya sea el de la filología del siglo XIX, el de la moda de nuestros días o el de la religión en la Edad Media, se descubren propiedades específicas, propias de un campo en particular, al tiempo que se contribuye al progreso del conocimiento de los mecanismos universales de los campos que se especifican en función de variables secundarias. Por ejemplo, debido a las variables nacionales, ciertos mecanismos genéricos, como la lucha entre pretendientes y dominantes, toman formas diferentes. Pero sabemos que en cualquier campo encontraremos una lucha, cuyas formas específicas habrá que buscar cada vez, entre el recién llegado que trata de romper los cerrojos del derecho de entrada, y el dominante que trata de defender su monopolio y de excluir a la competencia.

En consecuencia, los campos van apareciendo en la medida que se evidencian nuevas tensiones entre diferentes actores, debido a la aparición de múltiples intereses, en tanto que:

no hay un interés, sino intereses, variables según los tiempos y según los lugares, casi hasta el infinito. En mi lenguaje diré que hay tantos intereses como campos, como espacios de juego históricamente constituidos con sus instituciones específicas y sus leyes de funcionamiento propios. La existencia de un campo especializado y relativamente autónomo es correlativa de la existencia de compromisos y de intereses específicos (Bourdieu, 2000: 108).

Así las cosas, lastensiones entre actores con sus correspondientes intereses permite la aparición de un campo específico como la justicia transicional, dado que como bien lo explicó Bourdieu en las citas que anteceden, la especificidad derivada de relaciones entre actores y en un contexto determinado, permite la aparición de campos nuevos, como la moda contemporánea o la filología del siglo XIX, ejemplos dados por el mismo autor. 


\section{La estructuración de los campos}

Sin tensiones no hay juego entre actores y, por consiguiente, no hay campo, "es el estado de las relaciones de fuerza entre los jugadores lo que define la estructura del campo" (Bourdieu y Wacquant, 2005: 152). El campo depende para su aparición y subsistencia de sí mismo, por lo que no admite ninguna respuesta a priori (Bourdieu y Wacquant, 2005: 153). Cada campo se regula a sí mismo, por las fuerzas que subyacen en su interior, por ello "el principio de la dinámica de un campo yace en la forma de su estructura y, en particular, en la distancia, las brechas, las asimetrías entre las diversas fuerzas específicas que se confrontan entre sí" (Bourdieu y Wacquant, 2005: 155).

Cada campo se determina, de forma específica, por el capital que entra en juego en cada uno (Núñez Leiva, 2011: 212). "Las fuerzas que están activas en el campo $-\mathrm{y}$ por ende son seleccionadas por el analista como pertinentes debido a que producen las diferencias más relevantes- son las que definen el capital específico. Un capital no existe ni funciona salvo en relación con un campo" (Bourdieu y Wacquant, 2005: 155). En este mismo sentido, a propósito de la relación del capital con la estructura del campo, Bourdieu (2002: 120-121) explicitó que "hablar de capital específico significa que el capital vale en relación con un campo determinado, es decir, dentro de los límites de este campo, y que sólo se puede convertir en otra especie de capital dentro de ciertas condiciones".

Para Núñez Leiva (2011: 212) el capital obedece a un "concepto metaeconómico, que se predica de bienes que no tienen naturaleza económica, pero que respecto de ellos se puede observar la existencia de especies de mercados en los cuales circulan y se distribuyen entre sus distintos agentes". En el pensamiento de Bourdieu, existen varios tipos de capital, además del económico, configurado a partir de la posesión de bienes de contenido o significación económica. Entre los distintos tipos de capital definidos por Bourdieu se encuentran el capital cultural, que se refiere a los conocimientos adquiridos, así 
como a los códigos culturales; el capital social, que corresponde a los recursos que pueden ser movilizados por los actores en virtud de sus relaciones sociales y el capital simbólico el cual se conforma "por las categorías de percepción y juicio que permiten definir y legitimar valores y estilos culturales, morales y artísticos" (Chihu Amparán, 1998: 184). El capital simbólico implica las representaciones de poder y autoridad, las cuales pueden ser ostentadas por un actor en un contexto determinado (Téllez Iregui, 2002: 77).

Uno de los conceptos fundamentales en la teoría de Bourdieu, el cual también deviene en fundamental para la estructuración de los campos es el concepto de habitus, el cual "consiste en las disposiciones adquiridas y comunes de actores que pertenecen a un campo en particular" (Chihu Amparán, 1998: 185). El habitus es un producto histórico que tiene que ver con las apropiaciones adquiridas dentro de un campo determinado. Téllez Iregui (2002: 58) entiende al habitus:

como un sistema de disposiciones adquiridas, permanentes y transferibles, que generan y clasifican acciones, percepciones, sentimientos y pensamientos en los agentes sociales de una cierta manera, generalmente esperando a la conciencia y a la voluntad. Tales disposiciones suelen incorporarse desde la más temprana infancia, a lo largo de la vida de los individuos, mediante todo un proceso de socialización multiforme y prolongado que posibilita la apropiación del mundo, del yo y de los otros.

El habitus se convierte en un sistema generador de prácticas, a partir del contexto del campo en donde se desenvuelve, dado que, tal y como lo explica Bourdieu (2000: 111)

los agentes caen de alguna manera en la práctica que es la suya y no tanto la eligen en un libre proyecto o se ven obligados a ella por una coacción mecánica. Si es así, es que el habitus, sistema de disposiciones adquiridas en la relación con un cierto campo, se vuelve eficiente, operante, cuando encuentra las condiciones de su eficacia, es decir condiciones idénticas o análogas a aquellas de las que es producto". En consecuencia, el habitus aparece como un puente teórico entre el campo y el capital (Bourdieu y Wacquant, 2005: 179). 
De acuerdo con Morales de Setién Ravina (2005: 62) los campos se estructuran de conformidad con lo siguientes elementos: 1) Ser un espacio limitado; 2) Ser un espacio de lucha; 3) Ser un espacio definido mediante regularidades de conducta y reglas aceptadas; 4) Presentar momentos de crisis coyunturales, donde las reglas que hasta ese momento venían regulando el juego se cuestionan y 5) Ser un espacio donde la distribución de fuerzas es desigual. La limitación del espacio se refiere a la particularidad del campo, es decir que se trata de ese campo y no de otro; como espacio de lucha, en el campo debe ser claro quienes se encuentran enfrentados; como juego social, dentro del campo deben estar claras las reglas para participar en dicho juego; las crisis coyunturales se refieren a la posibilidad de que actores que no están en el juego puedan ingresar a los límites definidos en el campo para hacer parte del juego y el último aspecto, la distribución de fuerzas, hará referencia a la realidad en la distribución de fuerzas y a los factores que inciden en el otorgamiento de dichas fuerzas. Los elementos abordados en este acápite permiten el abordaje del estudio del campo de la justicia transicional a partir del estudio de los elementos que lo configuran.

\section{La configuración del campo de la justicia transicional}

La justicia transicional corresponde al modelo de justicia utilizado cuando se requiere una transición política, por lo tanto, aun cuando contiene elementos jurídicos, estos no son exclusivos ni excluyentes, dado que lo que hace especial a la justicia transicional, es precisamente la existencia de una transición, entendiendo esta como "el intervalo que se extiende entre un régimen político y otro" (O’ Donnell y Schmitter, 1994: 19). Es por ello que “el concepto justicia transicional contiene dos referentes a saber: el jurídico y el político. El jurídico se refiere al cumplimiento de los estándares internacionales enunciados, mientras que el político implica la transición en sí” (Rúa Delgado, 2016: 458). 
De conformidad con el concepto de campo de Bourdieu, la justicia transicional puede considerarse como un campo, en la medida en que cumple con las condiciones para su estructuración. En este sentido Gómez Sánchez (2014: 12), señala que:

la justicia transicional es un espacio en disputa en el que diferentes actores, con diferentes intereses, discursos y recursos, luchan por la conceptualización, el diseño y la aplicación de mecanismos para resolver conflictos políticos y hacer frente a las demandas de justicia por graves violaciones a los derechos humanos, en el contexto de una transición política.

Para la configuración del campo de la justicia transicional, siguiendo a Morales de Setién Ravina (2005: 62), lo primero corresponde a la limitación del espacio del campo. La justicia transicional se erige sobre relaciones de tipo político y jurídico, una imbricación entre ambos sin que sea uno solo. Gómez Sánchez (2014: 12-13) explica la relación de lo político con lo jurídico así:

... en épocas de guerra o de transición política, se presenta una ruptura en la situación política existente y emerge la idea de un nuevo momento fundacional que sirve de base a la nueva arquitectura institucional. En esta zona de intersección entre las reglas del juego político y las reglas de juego jurídico, los actores sociales entran en una intensa disputa sobre cómo definir la resolución del conflicto político, la instauración del nuevo momento fundacional y la manera como deben diseñarse los mecanismos legales para promover y facilitar los eventuales acuerdos políticos. Pero las implicaciones sociales de los procesos de transformación política van más allá de los simples diseños institucionales, pues las tensiones políticas y culturales continúan presentándose, tanto en espacios institucionales como no institucionales.

Un error muy común consiste en confundir la legislación de la justicia transicional con la justicia transicional en sí. La ley se encuentra inmersa en el campo jurídico, el cual, según Bourdieu (2001: 186-187) excluye a los profanos, es decir, a los actores no especializados que están en el juego. En la justicia transicional, a diferencia del campo jurídico, la legislación no es lo más 
importante, sino las tensiones que se generan entre diversos actores, todos los cuales deben entrar en el juego, actores no especializados, necesariamente. Si se parte de la base de que una de las condiciones para la aparición de la justicia transicional es la preexistencia de un conflicto, pues los actores que entran en juego son de diferentes tipos: institucionales (agentes gubernamentales, fuerzas militares y de policía, autoridades judiciales), actores ilegales de diferentes tipos (en el caso colombiano se presentan al tiempo guerrillas, paramilitares, narcotraficantes y bandas criminales) y movimientos sociales (movimientos de víctimas, desplazados, defensores de derechos humanos, movimientos campesinos y sindicales) (Trejos Rosero, 2013).

En una cita anterior (Bourdieu, 2002: 119-120) se indicó cómo, aun cuando los campos gozan de propiedades genéricas, diferentes variables nacionales que determinan el contexto del juego, inciden en la configuración del campo, en tanto que para el análisis del campo lo importante son las tensiones que se presentan y estas dependen de las circunstancias de tiempo, modo y lugar en las que se desarrolla el juego. Así, el campo de la justicia transicional construido a partir de las tensiones que se generan en un escenario como el colombiano guarda serias diferencias con un escenario diferente en donde se pueda configurar el campo a partir del análisis de otros jugadores, verbigracia con el escenario de Sudáfrica o con el de Irlanda del Norte, por citar solo dos ejemplos.

Se debe partir del hecho de que el conflicto corresponde al eje sobre el cual gravitan, inicialmente, los actores que entran en juego, razón por la cual las dimensiones del campo de la justicia transicional se trazan a partir del conflicto, de sus causalidades y de sus características. En el caso colombiano, el conflicto armado interno se considera como una confrontación interna de larga duración la cual "ofrece hoy imágenes y evidencia la superposición de circunstancias, causas, protagonistas y dinámicas tan disímiles que, para decirlo gráficamente, su desarrollo puede verse vía satélite al mismo tiempo que sus 
causas pueden remitir a una época de imágenes en sepia" (Pérez Toro, 2000: 14). Efectivamente, un conflicto de más de cinco décadas implica una representación caleidoscópica (Pécaut, 2013: 131) debido a la superposición, y sucesión, de actores y causalidades, de transformaciones que de forma permanente cambian el contexto, como lo dice Pécaut (2013: 26): "Los fenómenos de la violencia engendran su propio contexto. Las interacciones de todos los protagonistas de la violencia provocan nuevas regulaciones y nuevas percepciones".

El conflicto colombiano, en su génesis, encuentra dos causas principales: el problema de la inequitativa distribución de la tierra con los consecuentes reclamos de una reforma agraria que satisficiera los intereses de los campesinos y restituyera las tierras despojadas a campesinos e indígenas en distintas épocas, por una parte, y por la otra la exclusión de otras formas de participación política diferentes a la alternancia del poder bipartidista entre conservadores y liberales, lo cual se expresó, principalmente, en el denominado Frente Nacional, en donde el poder político, incluyendo la silla presidencial, fue alternado por cuatro períodos presidenciales (1958 a 1974), negando cualquier posibilidad a representaciones políticas de izquierda, por ejemplo, en una época de auge de la izquierda, precisamente, con el triunfo de la revolución cubana. Aun cuando las causas se pueden ver en sepia, siguiendo la metáfora de Pérez Toro (2000), la realidad contemporánea muestra múltiples transformaciones en los actores y en sus intereses.

Luego entonces, no es lo mismo pensar en las guerrillas colombianas de principios de la década de 1960, que en las guerrillas del siglo XXI; mientras las primeras surgían con un fuerte arraigo campesino, con banderas ideológicas identificables en los diferentes espectros de la izquierda y con una bandera común por la lucha por la tierra (Palacios, 2012: 67-98); las guerrillas contemporáneas parecieren haber perdido esa vinculación con las reivindicaciones históricas de los campesinos para participar del negocio del narcotráfico, aprovechando la dominación sobre vastas porciones del territorio (Pérez Toro, 2000: 17-18), 
además de su acercamiento a prácticas cercanas al terrorismo por la constante infracción al Derecho Internacional Humanitario (Fakhouri Gómez, 2014).

Así mismo, otros actores que entran en juego, como los grupos paramilitares, federados en una época en las Autodefensas Unidas de Colombia (AUC), juegan un papel fundamental en el campo de la justicia transicional, dado que con ellos se estrenó la legislación de justicia transicional en Colombia con la Ley 975 de 2005 o Ley de Justicia y Paz. Tanto paramilitares como guerrillas han contado con núcleos de apoyo al interior de la sociedad; los paramilitares, por una parte, con la ayuda, y en ciertos casos el patrocinio, de una "élite terrateniente que se ha ido gestando en torno a las mafias de la droga y las esmeraldas, con la vieja clase terrateniente que sobrevive con dificultad en las zonas de presencia guerrillera y con determinadas élites políticas y económicas regionales" (Pizarro Leongómez, 2004: 61). Igualmente las guerrillas han contado con el apoyo de algunos núcleos campesinos en sus zonas de influencia y con algunas redes de apoyo urbano. Los grupos paramilitares, a su vez, sufrieron una transmutación en las denominadas Bacrim, acrónimo para Bandas Criminales Emergentes que aparecieron sobre los restos de las mismas estructuras de las AUC (Aranguren Romero, 2012: 23). A mediados de la década del 2000 se desarrolló un proceso de paz entre el gobierno del entonces Presidente Álvaro Uribe Vélez con las AUC, lo cual terminó con la aparente desmovilización de las estructuras de estos grupos y su sometimiento a las reglas establecidas en la Ley de Justicia y Paz, lo que incluía una jurisdicción especial para pretender satisfacer los estándares internacionales en materia de verdad, justicia y reparación. Sin embargo, algunos críticos sostienen que el proceso de desmovilización no fue eficaz, dado que las estructuras paramilitares, precisamente transmutaron en las Bacrim.

El análisis del conflicto permite la identificación de los jugadores y de las tensiones que se presentan en el campo de la justicia transicional, dado que existe una extrapolación entre las relaciones de estos en el conflicto hacia el 
campo objeto de análisis. Por ello la delimitación del campo parte por reconocer la génesis de las relaciones en el conflicto, dado que no es posible pensar en justicia transicional sin la existencia de un conflicto previo. La relación con el conflicto, con sus causalidades, hace del campo de la justicia transicional un campo que trasciende lo jurídico, puesto que la normatividad de justicia transicional es tan solo uno de sus componentes.

El segundo elemento configurativo del campo tiene que ver con ser un espacio de lucha. Gómez Sánchez (2014: 13-14) se refiere a las tensiones en el campo de la justicia transicional de esta manera:

Entre las múltiples tensiones que se presentan en los procesos de justicia transicional quiero resaltar dos que merecen la mayor atención. La primera surge del conflicto entre las necesidades políticas percibidas en un determinado contexto y los valores normativos de justicia. No siempre las condiciones políticas y las necesidades percibidas coinciden con las demandas normativas, como ocurrió en el caso de la Segunda Posguerra Mundial, cuando las potencias militares decidieron procesar a los líderes del Gobierno nacionalsocialista. Las diferencias experiencias en Latinoamérica, Europa del Esta, África y Asia muestran que la definición política de la transición pasa por una negociación política compleja que responde, de un lado, a la necesidad de resolver el conflicto político y, del otro, a la demanda de aplicar sanciones a los responsables de violaciones masivas de derechos humanos.

La segunda tensión se relaciona con las contradicciones entre los intereses de grupos poderosos y los intereses y las perspectivas de sectores marginados socialmente. ¿Qué ocurre cuando las élites políticas que participan en las negociaciones de paz optan por establecer amnistías y perdones totales, y no se escuchan los reclamos ni las voces de las víctimas y de los sectores más vulnerables? La literatura contemporánea en justicia transicional y derechos humanos reconoce estas contradicciones con categorías como "justicia transicional desde arriba" y "justicia transicional desde abajo.

El primer grupo de tensiones referido por Gómez Sánchez (2014) en la cita enunciada, se refiere a las posibilidades de lucha contra la impunidad, para el cual se establecieron los estándares en derechos humanos en relación a la verdad, la justicia, la reparación y las garantías de no repetición; lo cual suele contraponerse a las demandas de impunidad de los actores ilegales, bajo 
las modalidades de perdón por amnistía o indulto, a cambio de la dejación de armas y la reincorporación a la vida civil, previo pacto de paz o cesación del conflicto. Estas tensiones se dan entre dos grupos de actores: las víctimas y los victimarios. Entre las primeras están todos los que demandan justicia por ser víctimas de violaciones a sus derechos humanos, con ocasión del conflicto armado de interno, sobresaliendo quienes padecieron desplazamiento forzado y las víctimas directas, o familiares, de conductas como desaparecimiento forzado, masacre, homicidio, secuestro, extorsión y demás conductas similares que, a la par de delitos, constituyen graves violaciones a los derechos humanos. El grupo de los victimarios, a su vez, está compuesto por todos los grupos armados ilegales, o incluso legales, que cometieron las violaciones a los derechos humanos mencionadas, con ocasión del conflicto. Se habla de actores legales porque el maridaje entre los grupos paramilitares y algunos sectores del ejército o de autoridades políticas, derivó en una especia de esquizofrenia de Estado (Giraldo, 2010, 2018), según la cual se "permitió una dislocación frente al rol del Estado y su posición de garante de los derechos de los asociados" (Rúa Delgado, 2015: 84). Estas tensiones principalmente se dan debido a un aparejamiento de la justicia con la justicia retributiva tradicional, por lo que cualquier intento de alternatividad en las sanciones será considerado como impunidad, tensiones que se presentan, sobre todo, entre las víctimas y los actores ilegales en tránsito hacia la legalidad (Cardona Chávez, 2012: 75).

El segundo grupo de tensiones identificado por Gómez Sánchez (2014) y que permite clarificar al campo de la justicia transicional como un espacio de lucha, es el que tiene que ver con la aparición de las perspectivas desde arriba y desde abajo en la justicia transicional (Gómez Sánchez, 2014: 17-18). La perspectiva desde arriba se refiere al trazo de políticas y de regulaciones, en materia de justicia transicional, desde la institucionalidad estatal (gobierno y legislativo). La perspectiva desde abajo se genera en espacios no institucionalizados, generalmente con el protagonismo de movimientos 
sociales, en donde los actores desarrollan procesos de reconciliación y de empoderamiento de las comunidades, a partir del desarrollo de iniciativas propias, como las de construcción de memoria, por ejemplo (Grupo de Memoria Histórica, 2009: 18).

El tercer elemento necesario para la configuración del campo corresponde a que el mismo es un espacio definido mediante regularidades de conducta y reglas aceptadas. Ello implica que el campo goza de una regulación interna propia. En un proceso de transición política de un "estado de conflicto a uno de posconflicto, o de un Estado autoritario a uno democrático, o de una situación de graves violaciones a los derechos humanos a una de reconciliación" (Rúa Delgado, 2015: 78), debe existir un fuerte marco normativo que permita sentar las bases de reconstrucción nacional y de sanación de las heridas dejadas por el conflicto en la sociedad. Sin un marco jurídico que garantice la transición, esta puede derivar en un fracaso (Rotberg, 2007: 225), lo que puede llevar, incluso, a un estado fallido.

El establecimiento de un marco jurídico sólido permite que la fase de justicia de la justicia transicional pueda desarrollarse como garantía de lucha contra la impunidad, en acatamiento de los estándares internacionales definidos en materia de verdad, justicia, reparación y garantías de no repetición. Si bien estos estándares pueden ser satisfechos a partir del establecimiento de políticas públicas, como en el caso colombiano con la política de reparación integral a las víctimas y la restitución de tierras derivada de la Ley 1448 de 2011, se requiere de un marco normativo sólido que garantice el cumplimiento de dichos estándares, sobre todo en lo que atañe a la justicia, verdadera novedad de la justicia transicional (Najar Moreno, 2009: 74), dado que las transiciones solían definir los aspectos jurídicos con amnistías o indultos para los actores armados ilegales.

El marco normativo permite definir pautas de juego para los actores del campo, dependiendo del rol que desempeñan, es así como en los procesos de 
justicia y paz seguidos en virtud de la Ley 975 de 2005 a los desmovilizados de las estructuras paramilitares de las AUC, por ejemplo, se determinan claramente las líneas de acción que deben seguir los postulados ante justicia y paz (desmovilizados) en la satisfacción de las cargas de verdad, justicia y reparación que recaen sobre ellos. Siendo estas cargas judiciales, verificables dentro de un proceso judicial, entre las luchas que se presentan en el campo, de acuerdo a lo descrito líneas arriba, subsisten tensiones en la forma de satisfacer cada carga, por ejemplo, en la verdad, puesto que lo que resulta del proceso es una verdad judicial, mas no una verdad histórica. Suele suceder que cada actor tiene su verdad, en tanto que esta termina siendo clave de justificación para múltiples acciones del pasado. Así la verdad de los combatientes ilegales, dentro de un proceso judicial de justicia y paz, termina siendo una verdad subjetiva difícil de corroborar, así el órgano investigador (la Fiscalía) tenga esta carga, que la mayoría de las veces termina siendo satisfecha a través de las confesiones de los postulados. Pero esta verdad suele chocar, en ocasiones, con la verdad que pueden tener las víctimas o con las demandas de verdad de las víctimas, cuando no la conocen, y ello sin contar con que a veces la verdad judicial entra en contradicción con intereses de élites políticas y económicas que jugaron su parte dentro del conflicto como auspiciadores de prácticas de violencia y como financiadores de algunos de los actores ilegales.

En el mismo sentido se puede realizar un análisis similar para la reparación, en donde a pesar de que existen normas legales respecto a la reparación que se debe hacer y existe claridad frente a los diferentes tipos de reparación, dentro de las luchas es inevitable que se presenten múltiples tensiones entre víctimas, victimarios y actores institucionales (Fiscalía, jueces, Unidad de Víctimas, etc.) frente a la eficacia de la reparación o a las formas de reparación.

Este punto de la existencia de reglas de juego claras al interior del campo está intrínsecamente relacionado con el cuarto elemento en la configuración del 
campo, el cual corresponde a las coyunturas que se presentan en las reglas del juego, lo cual tiene dos posibilidades a saber: por una parte, puede existir una transmutación entre los actores y, por la otra, pueden ingresar y salir al juego nuevos actores, lo que implica un reajuste permanente de las reglas.

La primera posibilidad, la transmutación de actores implica que estos puedan confundirse con otros o que el cambio se derive de nuevos contextos. En el campo de la justicia transicional es muy frecuente que los victimarios no se reconozcan como tales sino también como víctimas. Si se atiende a las causas históricas del conflicto, es muy probables que, en principio, quienes hoy son victimarios, en su momento fueron víctimas de otros; verbigracia, en el caso de las guerrillas colombianas, estas suelen presentarse como víctimas de las élites que propiciaron la exclusión política del mediados del siglo XX, además de mostrarse como víctimas del despojo de tierras o de procesos como el denominado período de la Violencia, el cual se dio entre fines de la década de 1940 y finales de la década de 1950, y que arrojó al país a las garras de una guerra bipartidista entre liberales y conservadores, erigida sobre el cadáver del caudillo liberal Jorge Eliécer Gaitán. A su vez los paramilitares se presentan como víctimas de las guerrillas, que en su actuar dejaron una estela de extorsiones, secuestros y homicidios. En principio, tanto guerrilleros como paramilitares tendrían razón al presentarse como víctimas, dado que sufrieron procesos de victimización, entendida esta como "aquella afectación que una persona recibe en su esfera jurídica por conductas o hechos humanos y de la naturaleza que deterioran su estatus social-jurídico" (Rodríguez Campos y García Mercader, 2014: 17-18). Ahora, si bien pueden tener razón en que los procesos de victimización que están en las causales históricas del conflicto, su rol en el mismo pasó al de ser originadores de los procesos de victimización y en ese sentido se les impone, dentro de las reglas judiciales, la satisfacción de las cargas de verdad, justicia, reparación y garantías de no repetición, sin que por ello se excluyan casos particulares de victimarios que pueden atender más al 
rol de víctimas, como los menores objeto de reclutamiento por organizaciones ilegales, así hubiesen cometido delitos dentro del conflicto, o las mujeres miembros de estos grupos que, a su vez, fueron sometidas a abortos forzados o a delitos sexuales. Como se nota con los ejemplos traídos a colación, en el campo de la justicia transicional se presenta, con frecuencia, la transmutación de actores, lo cual da lugar a las coyunturas en el manejo de las reglas que rigen el juego.

El segundo supuesto tiene que ver con el ajuste permanente de actores dentro del juego, por la entrada y salida de actores nuevos. En el caso de la justicia transicional, la connivencia de sectores de la institucionalidad (militares, políticos, jueces) con sectores ilegales (paramilitares, guerrillas), genera un dinamismo permanente en el estatus del campo, tanto que estas alianzas, con frecuencia, salen a relucir en los procesos judiciales y resulta menester el inicio de los respectivos procesos para ellos, con el agravante que, al no ser desmovilizados o no pertenecer a la estructura del grupo armado ilegal, en estricto sentido, son objetos de juzgamiento por la jurisdicción ordinaria y no por la jurisdicción de justicia transicional, la cual resulta más gravosa. Así se presenta el absurdo de que un político o un militar que prestó apoyo a una organización ilegal, puede resultar con una condena mucho más grave y por menos delitos, que la condena que se puede dar dentro de un proceso de justicia y paz, por ejemplo. En este mismo análisis caben las sanciones a los militares que, dentro de su rol en el conflicto, cometieron violaciones a los derechos humanos contra miembros de los grupos que estaban combatiendo, lo cual es juzgado a la luz de normas ordinarias mucho más gravosas que las de justicia transicional. En suma, múltiples tensiones que generan coyunturas dentro de las reglas de juego pactadas, tensiones que son dinámicas y, la mayoría de las veces, reiteradas.

Los cuatro puntos anteriores permiten un acercamiento al quinto elemento configurativo del campo, el cual corresponde a la distribución desigual 
de fuerzas al interior del campo. En todo campo la lucha es por el capital y en el campo de la justicia transicional la lucha es por el capital simbólico puesto que de este dependen las representaciones que se obtengan de cara a la obtención del poder político en momentos de la transición, por ello las tensiones se presentan por la búsqueda de una legitimación a partir de la justificación de las acciones, no en vano "la disputa por la legitimidad política, es decir, la lucha por el derecho moral de gobernar a la sociedad" (Trejos Rosero, 2013: 66) constituye el eje de las negociaciones que desembocan en la transición política. Si no fuera así los conflictos solo finalizarían con el exterminio del oponente, dado que, como bien lo señala Llano Ángel (2006: 105) "lo que está en juego en Colombia no es la paz sino la existencia misma del poder político, la configuración de una identidad nacional democrática y la construcción de un auténtico Estado Social de Derecho en todo el territorio nacional". Ahora bien, dentro del juego, ese capital simbólico es objeto de lucha permanente por parte de los actores, tanto de los legales como de los ilegales. Esa lucha es desigual en tanto que los recursos con los que se cuentan para afrontarla son diferentes. Una muestra de ello la constituyen las perspectivas desde arriba y desde abajo a las que se hizo alusión anteriormente. En la perspectiva desde arriba, los actores estatales cuentan con toda la institucionalidad a su servicio, partiendo del diseño de las políticas públicas y del manejo del presupuesto asignado; incluso, en un proceso de reconciliación nacional, los actores ilegales se pueden ver beneficiados de la institucionalidad puesta al servicio de la reconciliación, lo cual implica representación y visibilidad, es decir, capital simbólico, muy al contrario de los movimientos sociales como las organizaciones de víctimas, quienes al no contar con los mismos recursos, deben acudir a la perspectiva desde abajo, para traducirla en empoderamiento comunitario. 


\section{Conclusión}

La justicia transicional cumple con las condiciones para ser considerada como un campo autónomo, desde la teoría de los campos de Bourdieu. Si bien, cuenta con elementos que pueden resultar comunes al campo jurídico y al campo político, las particularidades que se presentan en las tensiones entre actores, permiten un análisis de campo a partir de sus elementos constitutivos. Las luchas entre actores por el capital simbólico que, por tratarse de actores que migraron de un conflicto hacia la búsqueda de una transición, se traduce en la lucha por el poder político, no simplemente a través de las ganancias de unas elecciones, sino por el derecho a gobernar como razón justificatoria. Se toma como base de análisis el caso colombiano, por tratarse del momento y del espacio en donde dichas tensiones entre actores se encuentran en pleno desarrollo.

\section{Referencias}

Alexy, Robert (2001). "Una defensa de la fórmula de Radbruch", Anuario da Facultade de Dereito da Universidade da Coruña, 5, 75-96. Disponible en: http://ruc.udc.es/ dspace/bitstream/2183/2109/1/AD-5-4.pdf. [Consultado el 24 de abril de 2015].

Aranguren Romero, Juan Pablo (2012). La gestión del testimonio y la administración de las víctimas: el escenario transicional en Colombia durante la Ley de Justicia y Paz. Bogotá D.C.: Siglo del Hombre CLACSO.

Bourdieu, Pierre (2002). Campo de poder, campo intelectual: itinerario de un concepto. Buenos Aires: Montressor.

Bourdieu, Pierre (2001). Poder, derecho y clases sociales. Segunda edición. Bilbao: Editorial Desclée de Brouwer. 
Bourdieu, Pierre (2000). Cosas Dichas. Primera edición, segunda reimpresión. Barcelona: Gedisa.

Bourdieu, Pierre y Wacquant, Loïc J. D (2005). Una invitación a la sociología reflexiva. Buenos Aires: Siglo XXI Editores.

Cardona Chávez, Juan Pablo (2012). Derechos de las víctimas y de los postulados: tensiones en el proceso de justicia y paz. Bogotá D.C.: GIZ.

Chihu Amparán, Aquiles (1998). "La teoría de los campos en Pierre Bourdieu", Polis. Investigación y análisis sociopolítico y psicosocial, 179198. Disponible en: http://www.juridicas.unam.mx/publica/librev/rev/ polis/cont/19981/pr/pr8.pdf. [Consultado el 16 de febrero de 2015].

Fakhouri Gómez, Yamila (2014). “¿Guerrilleros? ¿Terroristas? Implicaciones de cara a la paz". En Jaime Bernal Cuéllar (Comp.), XXXV Jornadas Internacionales de Derecho Penal. Procesos de paz: derecho penal y justicia transicional (pp. 67-93). Bogotá D.C.: Universidad Externado de Colombia.

Giraldo, Javier (2010). Derechos humanos y cristianismo. Trasfondo de un conflicto. Segunda edición. Bogotá D.C.: Editorial El Búho.

Gómez Sánchez, Gabriel Ignacio (2014). Justicia transicional en disputa: una perspectiva constructivista sobre las luchas por la verdad,la justicia y la reparación en Colombia, 2002-2012. Medellín: Universidad de Antioquia.

Grupo de Memoria Histórica (2009). Memorias en tiempo de guerra: repertorio de iniciativas. Bogotá D.C.: Puntoaparte editores.

Leyton, Daniel (2014). "Social structure, its epistemological uses, and the construction of the subject in Bourdieu's sociology". Universum, 29 (2), $169-183$.

Llano Ángel, Hernando (2006). Análisis impertinentes: reflexiones sobre política y ética en la Colombia contemporánea. Cali: Pontificia Universidad Javeriana.

Morales de Setién Ravina, Carlos (2005).“La racionalidad jurídica en crisis: Pierre Bourdieu y Gunther Teubner". En Morales de Setién Ravina, Carlos et al. (Ed.), La fuerza del Derecho. Primera edición, segunda 
reimpresión. (pp. 13-76). Bogotá D.C.: Siglo del Hombre - Ediciones Uniandes.

Najar Moreno, Esperanza (2009). Derecho a la verdad y justicia transicional en el marco de aplicación de la Ley de Justicia y Paz. Bogotá D.C.: Grupo Editorial Ibáñez.

Núñez Leiva, J. Ignacio (2011). “Elementos básicos de la teoría de los campos sociales de Pierre Bourdieu. Apuntes para estudiantes y docentes de Derecho", Ars boni et aequi 7 (1) 209- 219. Disponible en: http://www.ubo.cl/icsyc/wp-content/uploads/2011/09/Art-10.$\mathrm{Nu} \%$ C3\%Blez.pdf. [Consultado el 21 de abril de 2015].

O'Donnell, Guillermo y Schmitter, Phillippe (1994). Transiciones desde un gobierno autoritario 4: Conclusiones tentativas sobre las democracias inciertas. Barcelona: Paidós.

Palacios, Marco (2012). Violencia pública en Colombia, 1958-2010. Bogotá D.C.: Fondo de Cultura Económica.

Papacchini, Angelo (2003). Filosofia y Derechos Humanos. Tercera edición, segunda reimpresión. Cali: Universidad del Valle.

Pécaut, Daniel (2013). La experiencia de la violencia: los desafios del relato y la memoria. Medellín: La Carreta Editores.

Pérez Toro, William Freddy (2000). "Guerra y delito en Colombia", Revista Estudios Políticos, 16, 11-41. Disponible en: http:// revistaestudiospoliticos.udea.edu.co/index.php/estudiospoliticos/ article/viewFile/16702/14482 [Consultado el 09 de mayo de 2015].

Pizarro Leongómez, Eduardo (2004). Una democracia asediada. Balance y perspectivas del conflicto armado en Colombia. Bogotá D.C.: Grupo Editorial Norma.

Quinche Ramírez, Manuel Fernando (2009). Los estándares de la Corte Interamericana y la Ley de Justicia y Paz. Bogotá D. C.: Universidad del Rosario.

Radbruch, Gustav (2009). Relativismo y Derecho. Segunda edición. Bogotá D.C.: Temis.

RodríguezCampos, Carlos y García Mercader, Emilio José(2014). Victimización 
y Desvictimización. Bogotá D. C.: Temis.

Rotberg, Robert I. (2007). "El fracaso y el colapso de los Estados - Nación.

Descomposición, prevención y reparación”. En Moncada Roa Patricia et al.

(Ed.), Los estados fallidos o fracasados: un debate inconcluso y sospechoso.

(pp. 151-237). Bogotá D.C.: Siglo del Hombre - Universidad de los Andes

- Pontificia Universidad Javeriana.

Rúa Delgado, Carlos Felipe (2016). "La justicia anamnética como construcción complementaria del paradigma de justicia transicional. Una mirada desde el caso colombiano", Revista Ius et Praxis, 22 (1), 455 - 492.

Disponible en: http:/www.revistaiepraxis.cl/index.php/iepraxis/article/ view/629/436 [Consultado el 29 de noviembre de 2016].

Rúa Delgado, Carlos Felipe (2015). "Los momentos de la justicia transicional en Colombia", Revista de Derecho, 43, 71-109. Disponible en: http://rcientificas.uninorte.edu.co/index.php/derecho/article/ view/6270/6745 [Consultado el 07 de julio de 2015].

Teitel, Ruti(2009). “Genealogía de la justicia transicional”, Revista Pensamiento Penal, 89, 1-27. Disponible en: http://new.pensamientopenal.com. ar/01092009/derechos humanos02.pdf. [Consultado el 23 de noviembre de 2014].

Téllez Iregui, Gustavo (2002). Pierre Bourdieu: conceptos básicos y construcción socioeducativa. Bogotá D.C.: Universidad Pedagógica Nacional.

Trejos Rosero, Luis Fernando (2013). “Colombia: una revisión teórica de su conflicto armado", Enfoques XI/18, 55 - 75. Disponible en: http:// www.revistaenfoques.cl/ index.php/revista-uno/article/view/52/34 [Consultado el 10 de julio de 2015].

Vassalli, Giuliano (2014). Fórmula de Radbruch y derecho penal. Bogotá D.C.: Temis.

Vizcarra, Fernando (2002). "Premisas y conceptos básicos en la sociología de Pierre Bourdieu", Estudios sobre las Culturas Contemporáneas, VIII (16), 55 - 68. Disponible en: http://www.culturascontemporaneas. com/contenidos/premisas_y_conceptos.pdf. [Consultado el 18 de abril de 2015]. 